\title{
Exposure and Toxicity Assessment of Ultrafine Particles from Nearby Traffic in Urban Air in Seoul, Korea
}

\author{
Ji-Yeon Yang ${ }^{1}$, Jin-Yong Kim ${ }^{1}$, Ji-Young Jang ${ }^{1}$, Gun-Woo Lee ${ }^{1}$, Soo-Hwan Kim ${ }^{1}$, \\ Dong-Chun Shin ${ }^{1,2}$, Young-Wook Lim ${ }^{1}$ \\ ${ }^{1}$ Institute for Environmental Research, Yonsei University College of Medicine, Seoul; ${ }^{2}$ Department of Preventive Medicine, \\ Yonsei University College of Medicine, Seoul, Korea
}

\begin{abstract}
Objectives We investigated the particle mass size distribution and chemical properties of air pollution particulate matter (PM) in the urban area and its capacity to induce cytotoxicity in human bronchial epithelial (BEAS-2B) cells.

Methods To characterize the mass size distributions and chemical concentrations associated with urban PM, PM samples were collected by a 10-stage Micro-Orifice Uniform Deposit Impactor close to nearby traffic in an urban area from December 2007 to December 2009. PM samples for in vitro cytotoxicity testing were collected by a mini-volume air sampler with $\mathrm{PM}_{10}$ and $\mathrm{PM}_{2.5}$ inlets.

Results The PM size distributions were bi-modal, peaking at 0.18 to 0.32 and 1.8 to $3.2 \mu \mathrm{m}$. The mass concentrations of the metals in fine particles (0.1 to $1.8 \mu \mathrm{m})$ accounted for 45.6 to $80.4 \%$ of the mass concentrations of metals in PM10. The mass proportions of fine particles of the pollutants related to traffic emission, lead (80.4\%), cadmium (69.0\%), and chromium (63.8\%) were higher than those of other metals. Iron was the dominant transition metal in the particles, accounting for $64.3 \%$ of the PM 10 mass in all the samples. We observed PM concentration-dependent cytotoxic effects on BEAS-2B cells.

Conclusions We found that exposure to $\mathrm{PM}_{2.5}$ and $\mathrm{PM}_{10}$ from a nearby traffic area induced significant increases in protein expression of inflammatory cytokines (IL-6 and IL-8). The cell death rate and release of cytokines in response to the $\mathrm{PM}_{2.5}$ treatment were higher than those with $\mathrm{PM}_{10}$. The combined results support the hypothesis that ultrafine particles from vehicular sources can induce inflammatory responses related to environmental respiratory injury.
\end{abstract}

Keywords Cell toxicity, Transition metals, Ultrafine particles, Vehicle source

\author{
Correspondence: \\ Young-Wook Lim, PhD \\ 50 Yonsei-ro, Seadaemun-gu, Seoul \\ 120-752, Korea \\ Tel: $+82-2-2228-1898$ \\ Fax: +82-2-392-0239 \\ E-mail: envlim@yuhs.ac
}

Received: February 18, 2013

Accepted: April 26, 2013

Published online: July 17, 2013

This article is available from: http:// e-eht.org/

\section{Introduction}

Environmental particulate air pollution is measured by a global sampling convention called particulate matter $10\left(\mathrm{PM}_{10}\right)$ that measures the mass of particles collected with a $50 \%$ efficiency for particles with an aerodynamic diameter of $10 \mu \mathrm{m}$. Attention has focused on $\mathrm{PM}_{10}$ in cities because that is where most deaths occur, where pollution is routinely monitored and hence any as- sociations are best seen. Typical urban $\mathrm{PM}_{10}$ is comprised of up to $50 \%$ by mass of combustion-derived, ultrafine carbon-centered particles with associated metals including transition metals. Other major components include ammonium salts of nitrogen, sulfur and chlorine plus geological dust and organic matter [1].

During the last decade or so, there has been growing concern about the influence of particulate air pollution on human health 
in urban areas. The adverse health effects caused by particles have usually been related to the mass concentration of particulate matter less than $10 \mu \mathrm{m}\left(\mathrm{PM}_{10}\right)$ or $2.5 \mu \mathrm{m}\left(\mathrm{PM}_{2.5}\right)$ in diameter, or to the chemical compositions of these two size fractions $[2,3]$. More recently, questions have been raised whether ultrafine particles ([UFP], particle diameter $<0.1 \mu \mathrm{m}$ ) could be the subgroup of particles responsible for most of the observed health effects [4-7].

In $\mathrm{PM}_{10}$ this fraction is mostly composed of combustion-derived, carbon-centered particles with associated hydrocarbons and metals. Donaldson and Stone [8] suggested that progress in understanding the effects of UFP in the lungs has been achieved largely through the use of surrogate particles such as ultrafine carbon black and titanium dioxide. Using these types of particles, UFP have been shown to cause oxidative stress and pro-inflammatory effects in a number of in vivo and in vitro models. The mechanism of generation of the oxidative stress is not understood, but appears related to the large particle surface area in some way. Modulation of calcium signaling also appears to be involved in the stimulation of cytokine release by macrophages in response to UFP. Effects of $\mathrm{PM}_{10}$ are seen on cardiovascular mortality and morbidity, as well as in the lung. Although the roles of UFP in these effects are not well understood, there are plausible pathways that remain to be explored [8]. Recent studies have proposed oxidative stress-induced inflammation as one of the major pathways of PM-induced respiratory diseases $[9,10]$. Intracellular and extracellular production of reactive oxygen species (ROSs) can activate a number of redox-sensitive signaling cascades that could, in turn, induce inflammatory responses [9-11]. The nature and degree of oxidative stress induced by particulate air pollution can depend on the chemical reactivity of the PM and the responses that they induce in specific cell populations [12].

Atmospheric particles are a complex, heterogeneous mixture of organic and inorganic compounds that are a result of primary emissions of pollutants, secondary reactions and re-suspension of dust and other particles generated by mechanical abrasion of surfaces such as tires and roads. These varied sources of particles not only determine the subsequent composition of the particle mixtures, but may also be responsible for their toxicological effects, as has been shown in the literature. Particle-related chemical compounds implicated as health hazards include: transition metals, organic carbon, elemental carbon, and polycyclic aromatic hydrocarbons (PAHs). This evidence has been generated with in vitro models utilizing residual oil flay ash, in vitro models with "real-world" particles [13], animal experiments [14] and epidemiological studies $[15,16]$, however, the experimental study of particle component interactions is particularly difficult due to the complexity of the mixtures [17].

Properties of UFP and their association with $\mathrm{PM}_{2.5}$ or $\mathrm{PM}_{10}$ are not well quantified. Only a few investigations concerning the chemical composition of UFP have been published. In addition to these there are numerous papers dealing with particle mass size distributions, from which it may, however, be difficult to extract any information concerning UFP. A few review articles on size distribution measurements exist.

We investigated particle mass size distributions and chemical properties in the urban area and the capacity of air pollution PM to induce cytotoxicity in human bronchial epithelial (BEAS2B) cells.

\section{Materials and Methods}

\section{Sampling Site and Periods}

The PM sampling site in ambient air was a nearby roadside in urban air in Seoul, Korea. The distance from the sampling site to the road was $10 \mathrm{~m}$ and the volume of traffic per day was approximately 5,300 vehicles (gasoline 49\%; diesel 20\%; LPG 31\%).

The sampling was performed daily during December 2007 to December 2009 except during unusual weather phenomena such as rain, snow, or Asian dust (yellow sand).

\section{Particulate Sample Collection}

To characterize the mass size distributions of water-soluble inorganics associated with urban PM, the PM samples were collected by a 10-stage Micro-Orifice Uniform Deposit Impactor (MOUDI). The PM size ranges for each stage of the MOUDI were 18 to 10,10 to $5.6,5.6$ to $3.2,3.2$ to $1.8,1.8$ to $1.0,1.0$ to $0.56,0.56$ to $0.32,0.32$ to $0.18,0.18$ to 0.1 and 0.1 to $0.056 \mu \mathrm{m}$ of particle equivalent aerodynamic diameter. The flow rate of the MOUDI was $30 \mathrm{~L} / \mathrm{min} \pm 10 \%$ and Teflon filters (pore size $2.0 \mu \mathrm{m}$ ) were used for metals analysis.

PM samples to induce cytotoxic and inflammatory responses in vitro tests were collected by a mini-volume air sampler with $\mathrm{PM}_{10}$ and $\mathrm{PM}_{2.5}$ inlets. The sampling site and periods for $\mathrm{PM}_{10}$ and $\mathrm{PM}_{2.5}$ collection were the same as in the MOUDI study. The mini-volume air samplers for $\mathrm{PM}_{10}$ and $\mathrm{PM}_{2.5}$ were used to collect 24 hours at a flow rate of $5 \mathrm{~L} / \mathrm{min} \pm 10 \%$ on cellulose nitrate membrane filters (Hybond ECL RPN303D; Amersham Pharmacia Biotech, Inc., Little Chalfont, UK).

All the collecting substrates were weighed before and after the sampling using a filter microbalance. Before weighing, the samples were stored in a cool and dark room and then kept for about 24 hours in the weighing room at a relative humidity of 
about 30 to $40 \%$.

\section{Chemical Analysis}

Samples collected on filters by the MOUDI were extracted in $1 \mathrm{~N}$ nitric acid by microwave and direct analysis for metals using Atomic Absorption Spectrometry (Analyst 400; PerkinElmer Inc., Waltham, MA, USA). Metals that were quantified included cadmium $(\mathrm{Cd})$, chromium $(\mathrm{Cr})$, copper $(\mathrm{Cu})$, iron $(\mathrm{Fe})$, lead $(\mathrm{Pb})$, manganese $(\mathrm{Mn})$, and nickel $(\mathrm{Ni})$ for each stage of the MOUDI. The metal recovery rate was $96.4 \%$, and the limit of detection was less than $10 \mathrm{ng}$ for each metal.

$\mathrm{PAH}$ compounds analysis in $\mathrm{PM}_{10}$ and $\mathrm{PM}_{2.5}$ was performed in an accredited chemical analysis laboratory using the United States Environmental Protection Agency method [18]. Sixteen PAH compounds were identified and measured: naphthalene, acenaphthylene, acenaphthene, fluorene, phenanthrene, anthracene, fluoranthene, pyrene, benzo(a)anthracene, chrysene, benzo(b)fluoranthene, benzo(k)fluoranthene, benzo(a)-pyrene, dibenzo(a,h)anthracene, indeno(1,2,3-cd)pyrene, and benzo(g,h,i)-perylene. Filters were subjected to a 16 hours extraction with $200 \mathrm{~mL}$ methylene chloride in a soxhlet apparatus. The extracts were concentrated to $3 \mathrm{~mL}$ by evaporation followed by nitrogen evaporation of the solvent and then transferred for analysis into $1 \mathrm{~mL}$ vials using hexane. The soluble organic fraction was analyzed using a gas chromatograph (Hewlett-Packard 5890A; Agilant Technologies, Santa Clara, CA, USA) with a DB-5 fused silica capillary column (30 $\mathrm{m} \times 0.25 \mathrm{~mm}$ i.d. $\times 0.25 \mu \mathrm{m}$ film thickness), a mass selective detector (Hewlett- Packard 5972), and a computer workstation. The column temperature was set at $150^{\circ} \mathrm{C}$ for 5 minutes and then was increased to $300^{\circ} \mathrm{C}$ at $10^{\circ} \mathrm{C} / \mathrm{min}$ where it was held for 10 minutes for the analysis. Helium was used as the carrier gas, running at 60 to $80 \mathrm{psi}$. The PAHs recovery rate was $82.6 \%$, and the limits of detection for $16 \mathrm{PAH}$ compounds were ranged from 1 to $5 \mathrm{ng}$.

\section{Cell Toxicity}

\section{Preparation of Particles for Assay}

To obtain extractable organics matter (EOM) from $\mathrm{PM}_{10}$ and $\mathrm{PM}_{2.5}$, the samples were extracted using dichloromethane in an ultrasonic bath, then the absolute EOM were dried and weighted. The EOM samples were kept at $-80^{\circ} \mathrm{C}$ until in vitro assay. Prior to use, the EOM samples from $\mathrm{PM}_{10}$ or $\mathrm{PM}_{2.5}$ were diluted with dimethylsulfoxide, then surged for 10 minutes and mixed fully.

\section{Cell Culture}

A human bronchial epithelial cell line BEAS-2B (ATCC, CRL-9609) was purchased from the Korean Cell Line Bank in 2007. BEAS-2B cells were grown in minimum essential medium eagle (MEM) supplemented with $10 \%$ heat inactivated fetal bovine serum (WelGENE Inc., Daegu, Korea). The cells were grown in a humidified incubator at $37^{\circ} \mathrm{C}(95 \%$ room air, $5 \%$ $\mathrm{CO}_{2}$ ). The experiments used triplicate wells for each treatment level and either six or nine wells per culture plate were allocated as controls. Positive controls were included to monitor changes in the BEAS-2B cell response. All experiments were replicated with at least two independent cell passages.

\section{Cell Viability Assay}

The detection sensitivity using cell counting kit- 8 assay ([CCK-8], Dojindo, Kumamoto, Japan) is higher than that using other tetrazolium salts such as 3-(4,5-Dimethylthiazol-2-yl)2,5-Diphenyltetrazolium Bromide, 2,3-bis-(2-methoxy-4-nitro-5- sulfophenyl)-2H-tetrazolium-5-carboxanilide, and 3-(4,5-dimethylthiazol-2-yl)-5-(3-carboxymethoxyphenyl)-2(4-sulfophenyl)-2H-tetrazolium or water soluble tetrazolium salts, 2-(2-methoxy-4nitrophenyl)-3-(4-nitrophenyl)-5-(2,4-disulfophe-nyl)-2H-tetrazolium, and monosodium salt, being nonradioactive, enables sensitive colorimetric assays for the determination of the number of viable cells in cell proliferation and cytotoxicity assays. CCK- 8 is reduced by dehydrogenases in cells to give an orange colored product (formazan) that is soluble in the tissue culture medium. After treatment of the cells with EOMs from $\mathrm{PM}_{10}$ or $\mathrm{PM}_{2.5}$ as described above, the supernatant medium was replaced by $15 \mu \mathrm{L} /$ well CCK-8 solution and incubated for 2 hours. The colored supernatants without particles were transferred into a clean 96-well plate and measured at $450 \mathrm{~nm}$ [19].

\section{Determination of Cytokines}

The culture supernatants obtained from the CCK- 8 assay were analyzed for the release of pro-inflammatory cytokines such as interleukin-6 (IL-6) and interleukin-8 (IL-8). Quantitative determination of the cytokines IL- 6 and IL- 8 in the culture medium from exposed BEAS-2B cells was performed using sandwich enzyme linked immuno sorbant assay ([ELISA], OptEIA $^{\mathrm{TM}}$; BD Biosciences, San Diego, CA, USA). The analyses were performed according to the manufacturer's instructions. For IL-6, we used both a commercial kit (R\&D Systems, Minneapolis, MN, USA) and plates prepared with anti-human IL-6, biotin-conjugated anti-human IL-6, and avidin-horseradish peroxidase from eBioscience (San Diego, CA, USA). All IL-6 values were quantified using an R\&D Systems recombinant human 
IL-6 standard. The IL-8 ELISA used the R\&D Systems duo set

IL-8 development kit antibodies and standard.

\section{Measurement of Glutathione Levels}

Levels of intracellular glutathione (GSH) equivalents were determined using a colorimetric detection assay. Cells were scraped and collected by centrifugation. Each cell pellet was resuspended in 5\% metaphosphoric acid (Sigma-Aldrich, St. Louis, MO, USA) and the supernatant was collected to determine total GSH concentration using a commercial kit according to the manufacturer's protocol (BioVision Research Products, Mountain View, CA, USA). The absorbance at $405 \mathrm{~nm}$ was read by a microplate reader. The reduced GSH concentration was obtained by subtracting the oxidized from the total concentration. A duplicate culture with the same treatments was used to determine the total protein levels.

\section{Statistical Analysis}

Student's $t$-test and the Dunnett's test option in the SAS version 9.2 (SAS Inc., Cary, NC, USA) statistical program were used to determine the statistical significance $(p<0.05)$ of differences between treatment conditions.

\section{Results}

\section{PM Levels and Size Distribution}

The average monthly sampling concentrations of $\mathrm{PM}_{10}$ and $\mathrm{PM}_{2.5}$ at the sampling site on the nearby roadside were 34 to 124 $\mu \mathrm{g} / \mathrm{m}^{3}$ and 20 to $80 \mu \mathrm{g} / \mathrm{m}^{3}$, respectively. The average levels of $\mathrm{PM}_{10}$ and $\mathrm{PM}_{2.5}$ were $77.7 \pm 17.9 \mu \mathrm{g} / \mathrm{m}^{3}$ and $45.6 \pm 11.0 \mu \mathrm{g} / \mathrm{m}^{3}$, respectively. The levels of $\mathrm{PM}_{10}$ and $\mathrm{PM}_{2.5}$ showed seasonal vari- ations, with the highest in the winter and the lowest in the summer. The ratio of $\mathrm{PM}_{2.5}$ to $\mathrm{PM}_{10}$ levels varied from 41.4 to $43.0 \%$ (Figure 1).

Total concentrations of all size fractions ranged from 40.16 to $109.35 \mu \mathrm{g} / \mathrm{m}^{3}$ and average concentration of PM using the MOUDI was $59.13 \mu \mathrm{g} / \mathrm{m}^{3}$. The size distribution of PM was bimodal with peaks at 0.18 to $0.32 \mu \mathrm{m}$ and 1.8 to $3.2 \mu \mathrm{m}$. The percentages of UFP $(<0.1 \mu \mathrm{m})$, fine particles $(0.1$ to $1.8 \mu \mathrm{m})$ and coarse particles ( 1.8 to $10.0 \mu \mathrm{m}$ ) were $7.0 \%, 58.5 \%$, and $34.5 \%$, respectively. The PM levels using to the MOUDI were showed typical seasonal variations, however, the bimodal distribution of PM sizes was similar in all seasons (Figure 2). The level of fine particles on weekends was less than on weekdays. The average volumes of traffic per day on the weekdays and weekend were approximately 6,140 vehicles and 3,060 vehicles, respectively, at the sampling site. The level of fine particles in smoggy days $\left(\mathrm{PM}_{1.0} 29.2 \mu \mathrm{g} / \mathrm{m}^{3}\right)$ was higher than on smog-free days $\left(\mathrm{PM}_{1.0}\right.$ $24.2 \mu \mathrm{g} / \mathrm{m}^{3}$ ) and the level below $\mathrm{PM}_{0.1}$ was not affected by smog $\left(3.6 \mu \mathrm{g} / \mathrm{m}^{3}\right.$ on smoggy day and $4.1 \mu \mathrm{g} / \mathrm{m}^{3}$ on smog-free day) (Figure 3).

\section{PMComponents}

\section{PAHs in $\mathrm{PM}_{10}$ and $\mathrm{PM}_{2.5}$}

The average total concentrations of $\mathrm{PAHs}$ in $\mathrm{PM}_{10}$ and $\mathrm{PM}_{2.5}$ were $80.5 \mathrm{ng} / \mathrm{m}^{3}$ and $63.3 \mathrm{ng} / \mathrm{m}^{3}$, respectively, and the congener patterns were similar in $\mathrm{PM}_{10}$ and $\mathrm{PM}_{2.5}$. The major congeners of PAHs were benzo[a]pyrene, benzo[b]fluoranthene, benzo $[\mathrm{g}, \mathrm{h}, \mathrm{i}]$ pyrene, pyrene, and benzo[k]fluoranthene (Figure 4). The percentages of PAHs in $\mathrm{PM}_{10}$ and $\mathrm{PM}_{2.5}$ were $0.10 \%$ and $0.14 \%$, respectively, the ratio of $\mathrm{PAH}$ levels in $\mathrm{PM}_{2.5}$ to $\mathrm{PAH}$ levels in $\mathrm{PM}_{10}$ was $78.6 \%$.

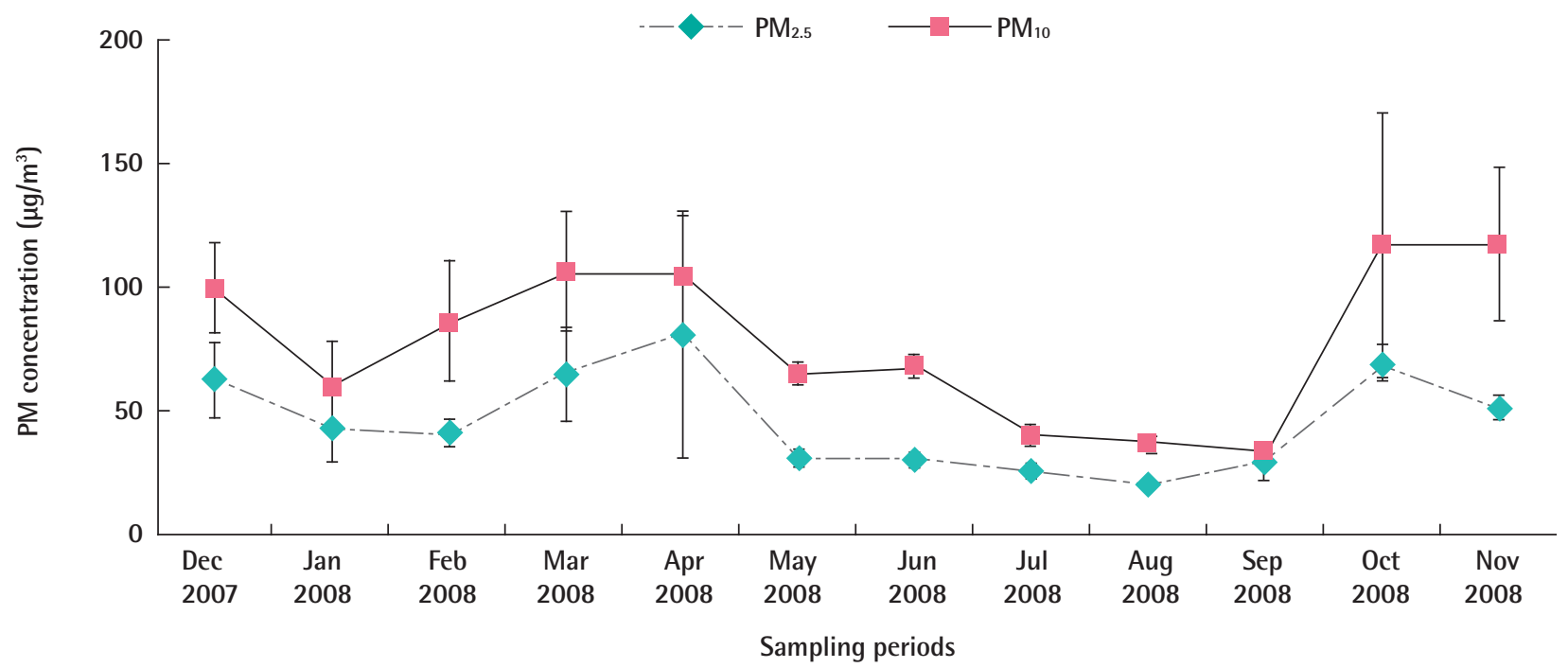

Figure 1. Average monthly concentrations of $\mathrm{PM}_{10}$ and $\mathrm{PM}_{2.5}$ at the sampling site. $\mathrm{PM}$, particulate matter. 


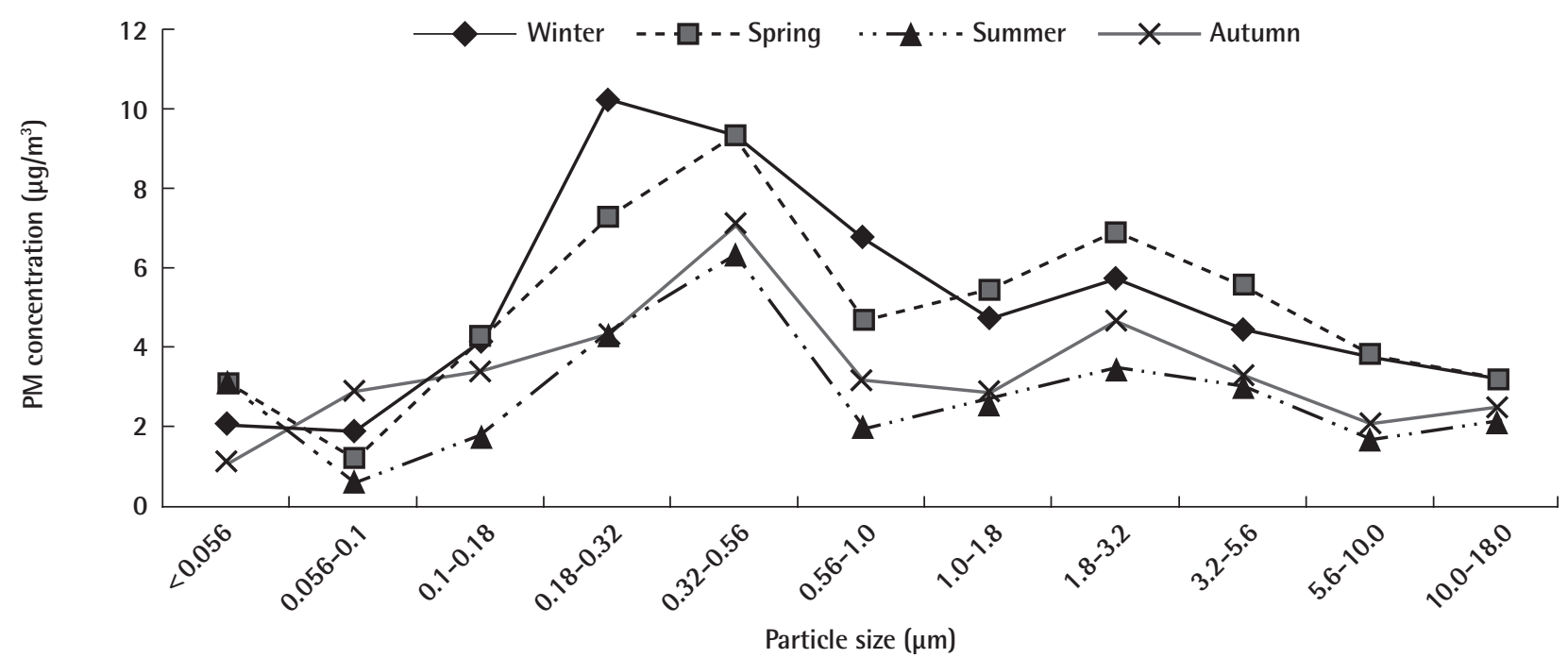

Figure 2. Size distributions of PM across the four seasons using the Micro-Orifice Uniform Deposit Impactor. PM, particulate matter.

Table 1. Concentration of metals according to particulate matter sizes

\begin{tabular}{|c|c|c|c|c|c|c|c|}
\hline \multirow{2}{*}{ Particle size $(\mu \mathrm{m})$} & \multicolumn{7}{|c|}{ Annual average concentration of metals $\left(\mu \mathrm{g} / \mathrm{m}^{3}\right)$} \\
\hline & $\mathrm{Cd}$ & $\mathrm{Cr}$ & $\mathrm{Cu}$ & $\mathrm{Fe}$ & $\mathrm{Pb}$ & $\mathrm{Mn}$ & $\mathrm{Ni}$ \\
\hline$<0.056$ & $0.03 \pm 0.04$ & $1.93 \pm 1.10$ & $4.12 \pm 2.80$ & $67.2 \pm 35.2$ & $1.75 \pm 0.37$ & $0.63 \pm 0.21$ & $0.97 \pm 1.37$ \\
\hline$<0.1$ & $0.08 \pm 0.08$ & $2.61 \pm 1.93$ & $5.11 \pm 3.07$ & $89.2 \pm 53.0$ & $1.63 \pm 1.02$ & $0.94 \pm 0.37$ & $0.81 \pm 0.39$ \\
\hline$<0.18$ & $0.15 \pm 0.10$ & $2.37 \pm 0.61$ & $6.45 \pm 4.97$ & $129.9 \pm 70.3$ & $4.25 \pm 2.37$ & $1.74 \pm 0.81$ & $0.83 \pm 0.35$ \\
\hline$<0.32$ & $0.27 \pm 0.18$ & $3.10 \pm 1.70$ & $8.70 \pm 5.59$ & $181.2 \pm 105.2$ & $6.84 \pm 4.81$ & $2.69 \pm 1.52$ & $1.11 \pm 0.93$ \\
\hline$<0.56$ & $0.23 \pm 0.12$ & $2.70 \pm 1.44$ & $7.25 \pm 6.06$ & $152.4 \pm 71.7$ & $8.35 \pm 5.03$ & $2.88 \pm 1.51$ & $1.56 \pm 1.53$ \\
\hline$<1.0$ & $0.21 \pm 0.18$ & $3.86 \pm 5.14$ & $6.32 \pm 4.51$ & $41.6 \pm 28.4$ & $9.33 \pm 8.41$ & $2.64 \pm 1.50$ & $4.69 \pm 8.68$ \\
\hline$<1.8$ & $0.08 \pm 0.07$ & $2.74 \pm 1.42$ & $7.30 \pm 5.39$ & $49.2 \pm 31.8$ & $3.17 \pm 2.62$ & $1.90 \pm 1.14$ & $1.28 \pm 0.93$ \\
\hline$<3.2$ & $0.07 \pm 0.11$ & $1.59 \pm 0.63$ & $7.91 \pm 6.87$ & $82.6 \pm 45.2$ & $2.72 \pm 2.14$ & $3.26 \pm 0.93$ & $3.63 \pm 4.99$ \\
\hline$<5.6$ & $0.23 \pm 0.32$ & $1.06 \pm 0.34$ & $12.10 \pm 13.72$ & $95.7 \pm 67.5$ & $1.55 \pm 0.48$ & $1.94 \pm 0.94$ & $3.94 \pm 3.73$ \\
\hline$<10.0$ & $0.01 \pm 0.01$ & $1.19 \pm 0.59$ & $4.26 \pm 4.24$ & $44.6 \pm 26.1$ & $1.13 \pm 0.47$ & $1.69 \pm 0.50$ & $1.97 \pm 2.29$ \\
\hline$<18$ & $0.04 \pm 0.03$ & $1.50 \pm 0.81$ & $13.07 \pm 14.10$ & $58.8 \pm 32.9$ & $0.86 \pm 0.29$ & $0.95 \pm 0.87$ & $4.31 \pm 3.53$ \\
\hline Total & $1.40 \pm 1.25$ & $24.64 \pm 15.72$ & $82.60 \pm 71.33$ & $992 \pm 567$ & $40.57 \pm 28.01$ & $21.29 \pm 10.30$ & $25.09 \pm 28.71$ \\
\hline
\end{tabular}

Cd, cadmium; Cr, chromium; Cu, copper; Fe, iron; Pb, lead; Mn, manganese; Ni, nickel.

\section{Metals in Ultra fine PM}

The average concentrations of $\mathrm{Pb}, \mathrm{Cd} \mathrm{Cr}, \mathrm{Cu}, \mathrm{Fe}, \mathrm{Mn}$, and $\mathrm{Ni}$ were 40.57, 1.40, 24.64, 82.60, 992.33, 21.29, and $25.09 \mu \mathrm{g} / \mathrm{m}^{3}$, respectively (Table 1 ). The mass concentrations of the metals in fine particles ( 0.1 to $1.8 \mu \mathrm{m}$ ) accounted for 45.6 to $80.4 \%$ of the total mass concentrations of metals in $\mathrm{PM}_{10}$. The mass proportions of fine particles for pollutants related to traffic emission, $\mathrm{Pb}$ (80.4\%), Cd (69.0\%), and Cr (63.8\%), were higher those for that other metals. Fe was the dominant transition metal in fine particles and accounted for $64.3 \%$ of the PM1.0 mass throughout all the samples.

\section{Cell Toxicity}

\section{Cell Viability}

Figure 5 shows cell viability of BEAS-2B cells that were exposed to a suspension of EOM-PM for 24 hours. We observed an EOM concentration-dependent cell death rate in BEAS-2B cells for $\mathrm{PM}_{10}$ and $\mathrm{PM}_{2.5}$. Seasonal patterns of BEAS-2B cells viability (Winter < Autumn, Spring $<$ Summer) were similar for $\mathrm{PM}_{10}$ and $\mathrm{PM}_{2.5}$. BEAS-2B cells viability decreased rapidly when exposed to more than $100 \mu \mathrm{g}-\mathrm{EOM} / \mathrm{mL}$ from $\mathrm{PM}_{2.5}$.

\section{Cytokine Release}

Cytokine (IL-6 and IL-8) release was dose-dependently increased in BEAS-2B cells after 24-hours exposure to EOM. IL-8 was more strongly secreted than IL-6, with a maximum of 800 $\mathrm{pg} / \mathrm{mL}$ per 24 hours. Both the $\mathrm{PM}_{10}$ and $\mathrm{PM}_{2.5}$ samples showed a peak of IL- 8 induction at $400 \mu \mathrm{g}-\mathrm{EOM} / \mathrm{mL}$. Cell death may limit the amount of IL-8 in the medium after 24-hour of treatment at the higher concentrations of $\mathrm{PM}_{10}$ in the summer and autumn. The IL-6 release in response to particle treatment was qualitatively similar to the IL-8 response. Although seasonal patterns of cytokine release by $\mathrm{PM}_{2.5}$ were not observed, cyto- 


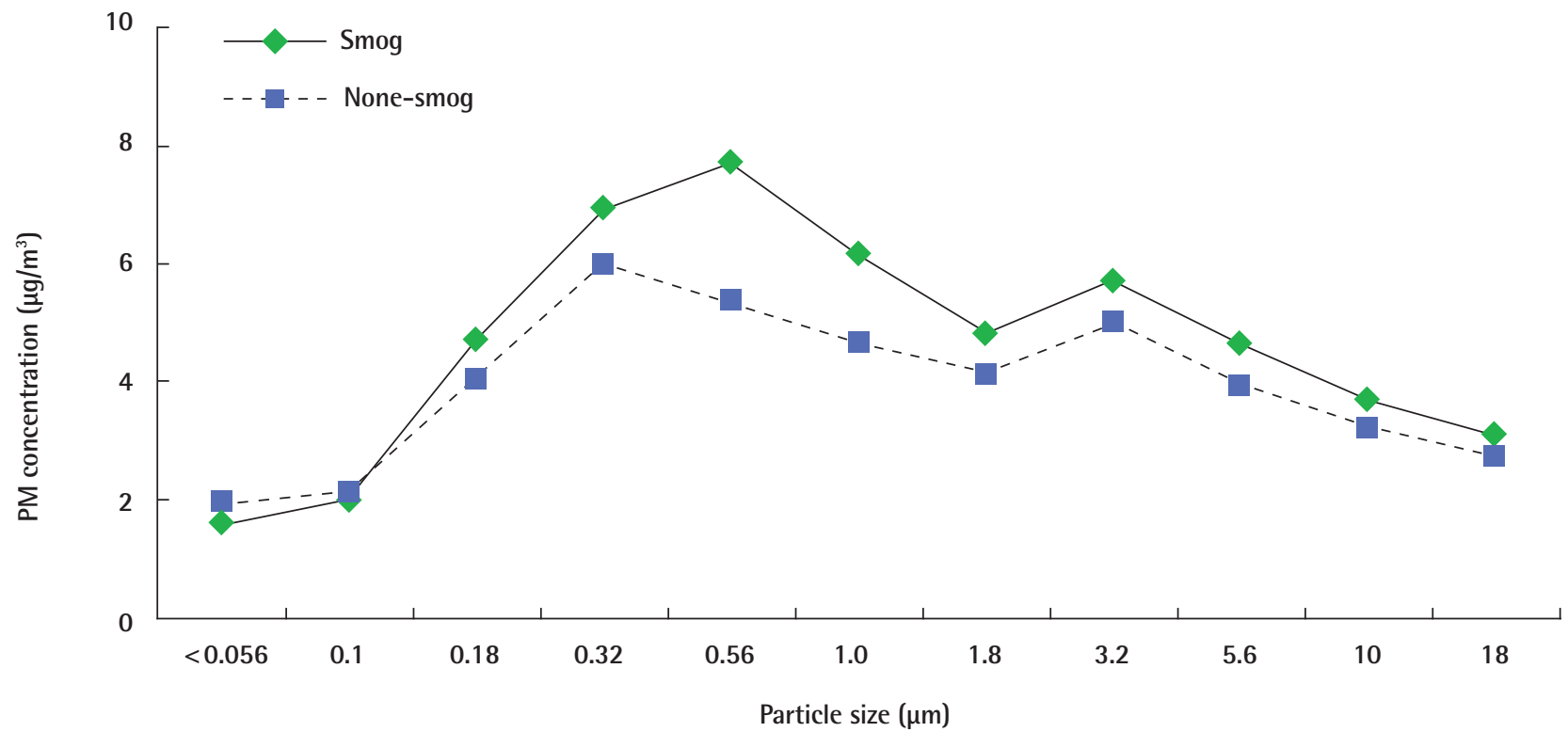

Figure 3. Size distributions of PM on smoggy and smog-free days using the Micro-Orifice Uniform Deposit Impactor. PM, particulate matter.

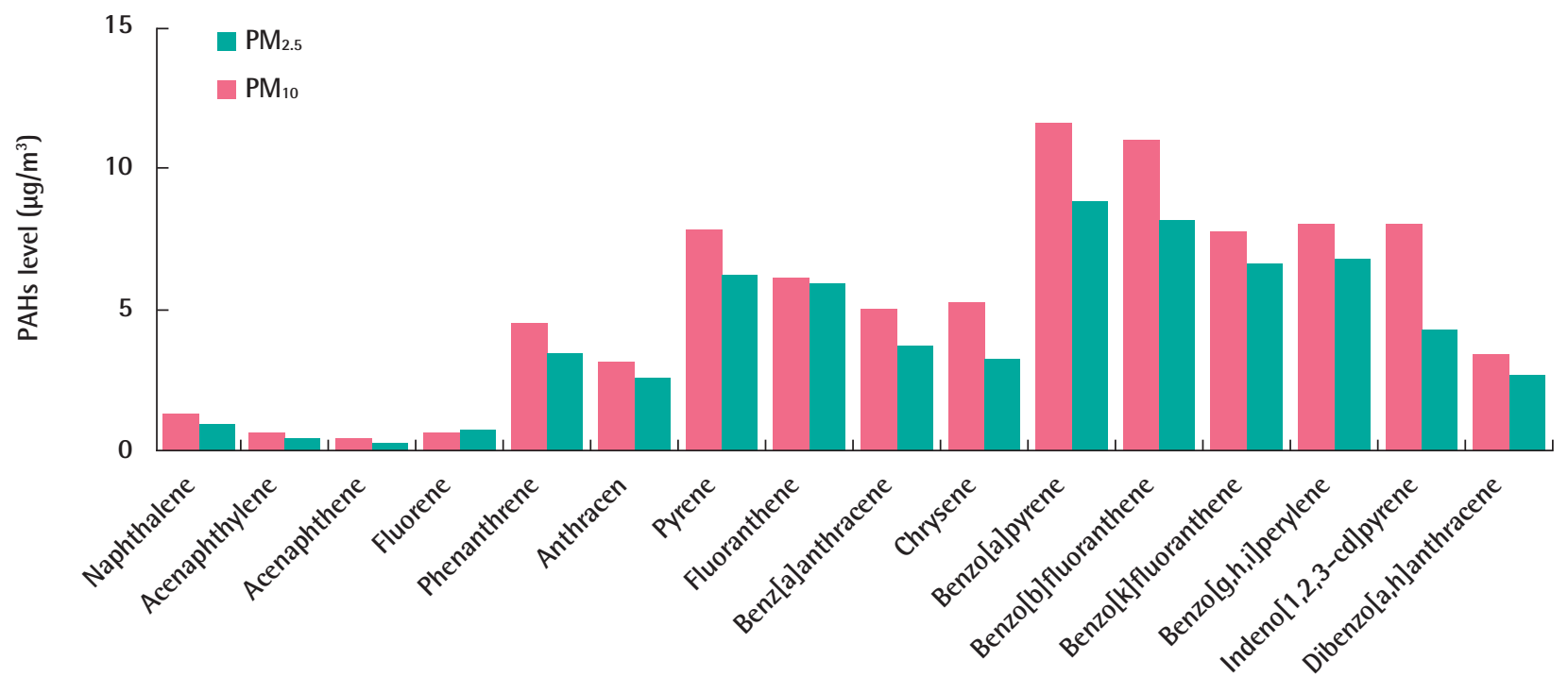

Figure 4. Congener patterns of polycyclic aromatic hydrocarbon (PAH) levels in $\mathrm{PM}_{2.5}$ and $\mathrm{PM}_{10}$. PM, particulate matter.

kine release by $\mathrm{PM}_{10}$ in the winter and spring was higher than that in summer and autumn. Cytokine release increased rapidly after exposure to more than $200 \mu \mathrm{g}-\mathrm{EOM} / \mathrm{mL}$ from $\mathrm{PM}_{10}$ or $\mathrm{PM}_{2.5}$ (Figure 6).

\section{Oxidative Stress}

Intratracheal instillation of $\mathrm{PM}_{10}$ and $\mathrm{PM}_{2.5}$ decreased GSH levels in a concentration-dependent manner. The GSH reduction ratio for $\mathrm{PM}_{2.5}(80 \%)$ was higher than that for $\mathrm{PM}_{10}(64 \%)$ and the GSH reduction ratio for PM in the winter was slightly higher than that in the summer (Figure 7).

\section{Discussion}

We measured particle mass size distributions and chemical properties in the urban area and the capacity of air pollution PM to induce cytotoxicity in human BEAS-2B cells. During the sampling period, the annual level of $\mathrm{PM}_{10}$ was less than $100 \mu \mathrm{g} / \mathrm{m}^{3}$ (the 24 hours air quality standard for $\mathrm{PM}_{10}$ in Korea), but exceeded $50 \mu \mathrm{g} / \mathrm{m}^{3}$ (the annual air quality standard for $\mathrm{PM}_{10}$ in Korea) because this site was near roadside traffic. Although we have not sampled during Asian dust storm days, the levels of $\mathrm{PM}$ in the spring were the most highest. There is an indirect effect of Asian dust storms in the spring period. The bimodal distribution of PM sizes in this study agrees with previous reports 

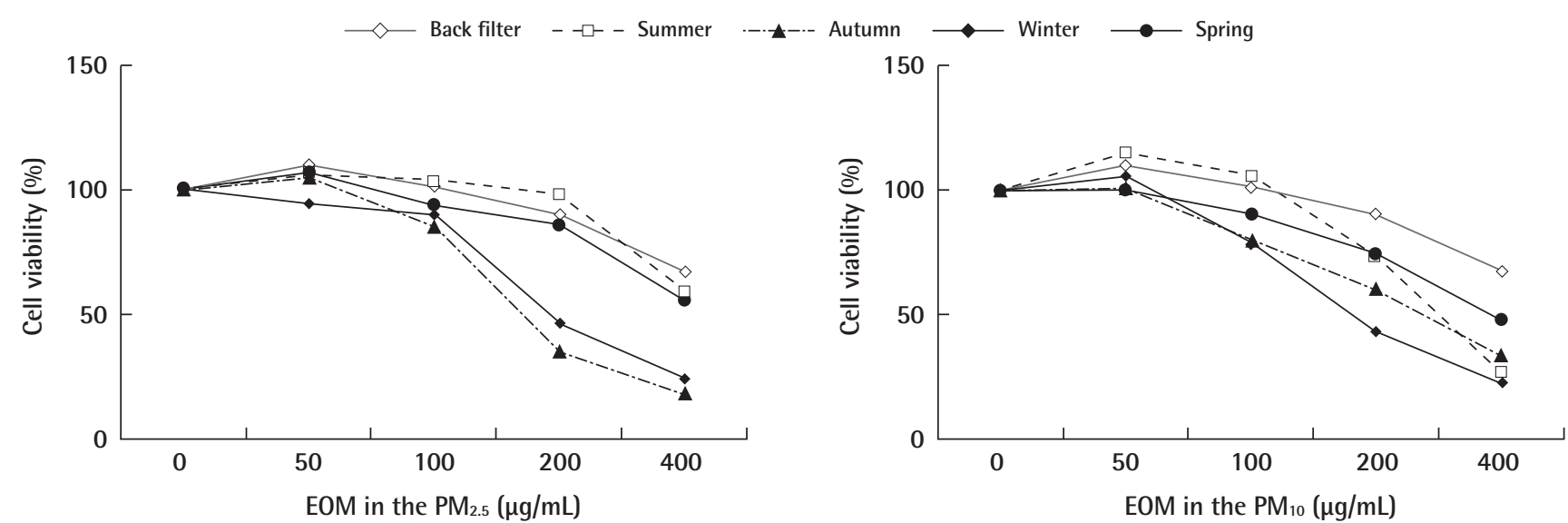

Figure 5. Cell viability of human bronchial epithelial cells exposed to EOM of $\mathrm{PM}_{10}$ and $\mathrm{PM}_{2.5}$ according to sampling periods. EOM, extractable organics matter; PM, particulate matter.
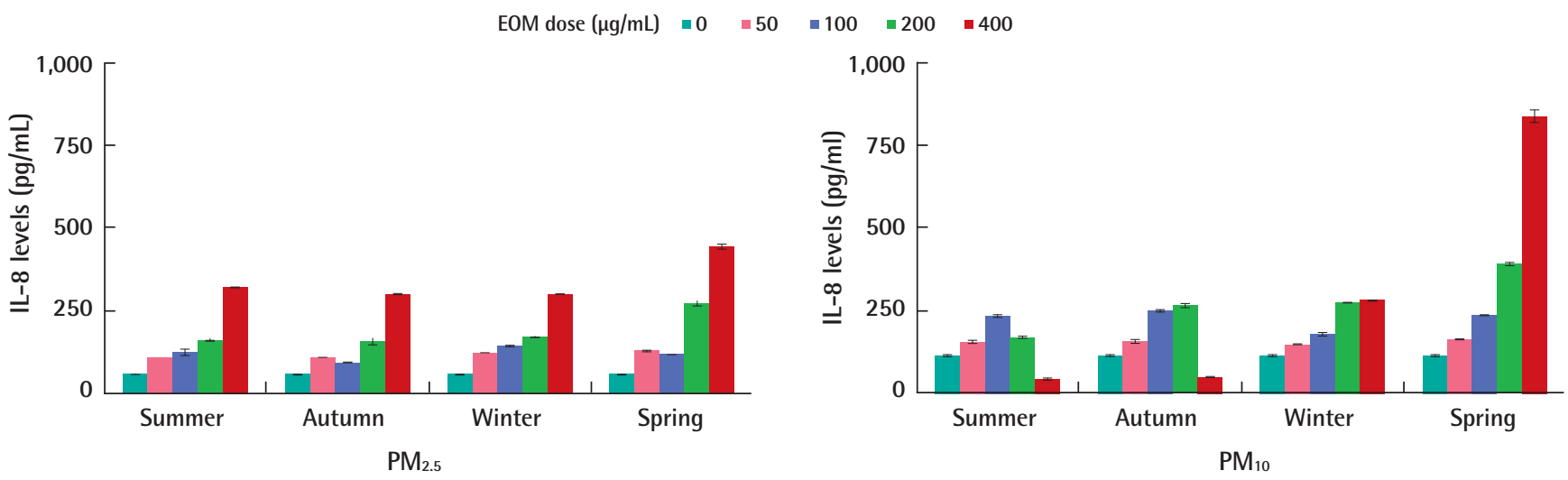

Figure 6. Levels of IL-8 expression in human bronchial epithelial cells exposed to EOM from $\mathrm{PM}_{10}$ and $\mathrm{PM}_{2.5}$. IL-8, interleukin-8; EOM, extractable organics matter; PM, particulate matter.

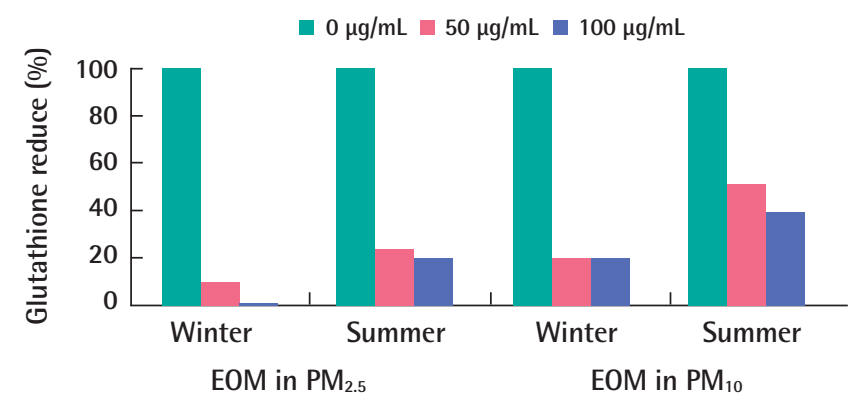

Figure 7. Reduced glutathione ratio in human bronchial epithelial cells exposed to EOM from $\mathrm{PM}_{10}$ and $\mathrm{PM}_{2.5}$. EOM, extractable organics matter; $\mathrm{PM}$, particulate matter.

$[20,21]$. The level of PM was also related to the daily traffic volume in this study, similar to other papers [22,23].

We found weak correlations between PM mass and the concentrations of chromium, copper, lead, and iron as in the previous studies $[24,25]$. The ratio of PAH levels in $\mathrm{PM}_{2.5}$ to PAH levels in $\mathrm{PM}_{10}$ was $78.6 \%$ and the percentage of PHAs in $\mathrm{PM}_{2.5}$ was higher than in $\mathrm{PM}_{10}$. Due to re-suspension of dust from the ground by the wind and/or traveling vehicles, the total ambient total PAHs, as well as $\mathrm{PM}_{2.5}$, are recognized to be mainly con- tributed from mobile sources; those larger than $\mathrm{PM}_{2.5}$ are similarly recognized to be contributed primarily by road dust $[26,27]$.

We showed that cell viability and cytokine release prompted by $\mathrm{PM}$ had seasonal variations. In particular, the higher cytokine release in the spring was considered an indirect affect of Asian dust storms in Korea, although we sampled so as to avoid Asian dust warning days. One such factor may be the content of organic compounds, which may vary in PM from different seasons. The PM contained more organic pollutants indicating incomplete combustion in the winter season and may produce more intense cell toxicity. These results also raise the hypothesis that ROSs produced from different sources may be associated with different PM-induced health effects. Several previous studies have shown that the association of PM with mortality or cardiovascular disease was stronger for the winter season [28-30]. IL- 8 is one of the most potent activators and chemoattractants for neutrophils, and it contributes to neutrophilic inflammation in chronic bronchitis and emphysema [31]. It has been shown to be a potent chemotactic factor for eosinophils and T-lymphocytes as well, and therefore may have a role in the pathophysiol- 
ogy of allergic airway disease [32]. Fujii et al. [33] showed that primary BEAS-2B cells exposed to ambient $\mathrm{PM}$ produce proinflammatory mediators such as leukemia inhibitory factor, granulocyte-macrophage colony-stimulating factor, IL-6, and IL-8. The GSH system, which includes both thiol and disulfide forms of GSH along with related enzymes, provides a good example of the variation in antioxidant capacity [34]. This result agrees with previous reports that PM particles had free radical activity in vivo and in vitro, as shown by a decrease in GSH levels $[34,35]$. Akhtar et al. [12] suggested that PM mass concentration had an inhibitory effect on cell viability and cytokine release, and insoluble constituents of particles played a dominant role in inducing both the cytotoxic and pro-inflammatory effects. Hetland et al. [36] and Seagrave et al. [37] examined the pro-inflammatory response of cells to PM in vitro, and reported dose-response profiles similar to those reported herein.

In summary, PM size distributions exhibited a bimodal ( 0.18 to 0.32 and 1.8 to $3.2 \mu \mathrm{m}$ ) pattern. Fe was the dominant transition metal in fine particles and accounted for $64.3 \%$ of $\mathrm{PM}_{1.0}$ mass throughout all the samples. We found that exposure to $\mathrm{PM}_{2.5}$ and $\mathrm{PM}_{10}$ from a nearby traffic area induced significant increases in protein expression of inflammatory cytokines (IL-6 and IL-8). The cell death rate and release of cytokines in response to the $\mathrm{PM}_{2.5}$ treatment were higher than those in response to $\mathrm{PM}_{10}$.

The combined results support the hypothesis that UFP from vehicular sources can induce inflammatory responses related to environmental respiratory injury.

\section{Acknowledgements}

This work was supported by KOSEF through the National Core Research Center for Nanomedical Technology (2008-81297) and KMOE through the ECO_STAR projects (33-1-304).

\section{Confilict of Interest}

The authors have no conflicts of interest with material presented in this paper.

\section{References}

1. Harrison RM, Jones M. The chemical composition of airborne particles in the UK atmosphere. Sci Total Environ 1995;168(3): 195-214.

2. Schwartz J, Norris G, Larson T, Sheppard L, Claiborne C, Koenig J. Episodes of high coarse particle concentrations are not associated with increased mortality. Environ Health Perspect 1999;107(5):
339-342.

3. Wilson WE, Suh HH. Fine particles and coarse particles: concentration relationships relevant to epidemiologic studies. J Air Waste Manag Assoc 1997;47(12):1238-1249.

4. Oberdorster G, Gelein RM, Ferin J, Weiss B. Association of particulate air pollution and acute mortality: involvement of ultrafine particles? Inhal Toxicol 1995; 7(1):111-124.

5. Seaton A, MacNee W, Donaldson K, Godden D. Particulate air pollution and acute health effects. Lancet 1995;345(8943):176178.

6. Peters A, Wichmann HE, Tuch T, Heinrich J, Heyder J. Respiratory effects are associated with the number of ultrafine particles. Am J Respir Crit Care Med 1997;155(4):1376-1383.

7. Donaldson K, Stone V, MacNee W. The toxicology of ultrafine particles. In: Howard V, Maynard RL; Royal Microscopical Society (Great Britain). Particulate matter: properties and effects upon health. Oxford: BIOS Scientific; 1999, p. 115-127.

8. Donaldson K, Stone V. Current hypotheses on the mechanisms of toxicity of ultrafine particles. Ann Ist Super Sanita 2003;39(3):405410.

9. Li N, Sioutas C, Cho A, Schmitz D, Misra C, Sempf J, et al. Ultrafine particulate pollutants induce oxidative stress and mitochondrial damage. Environ Health Perspect 2003; 111(4):455-460.

10. $\mathrm{Li} \mathrm{N}, \mathrm{Xia}$ T, Nel AE. The role of oxidative stress in ambient particulate matter-induced lung diseases and its implications in the toxicity of engineered nanoparticles. Free Radic Biol Med 2008;44(9): 1689-1699.

11. Kelly FJ. Oxidative stress: its role in air pollution and adverse health effects. Occup Environ Med 2003;60(8):612-616.

12. Akhtar US, McWhinney RD, Rastogi N, Abbatt JP, Evans GJ, Scott JA. Cytotoxic and proinflammatory effects of ambient and sourcerelated particulate matter (PM) in relation to the production of reactive oxygen species (ROS) and cytokine adsorption by particles. Inhal Toxicol 2010;22 Suppl 2:37-47.

13. Dreher KL, Jaskot RH, Lehmann JR, Richards JH, McGee JK, Ghio AJ, et al. Soluble transition metals mediate residual oil fly ash induced acute lung injury. J Toxicol Environ Health 1997;50(3): 285-305.

14. Saldiva PH, Clarke RW, Coull BA, Stearns RC, Lawrence J, Murthy $\mathrm{GG}$, et al. Lung inflammation induced by concentrated ambient air particles is related to particle composition. Am J Respir Crit Care Med 2002;165(12):1610-1617.

15. Mar TF, Norris GA, Koenig JQ, Larson TV. Associations between air pollution and mortality in Phoenix, 1995-1997. Environ Health Perspect 2000;108(4):347-353.

16. Dominici F, McDermott A, Daniels M, Zeger SL, Samet JM. Revised analyses of the National Morbidity, Mortality, and Air Pollution Study: mortality among residents of 90 cities. J Toxicol Environ Health A 2005;68(13-14):1071-1092.

17. Rosas Pérez I, Serrano J, Alfaro-Moreno E, Baumgardner D, GarcíaCuellar C, Martín Del Campo JM, et al. Relations between PM10 composition and cell toxicity: a multivariate and graphical approach. Chemosphere 2007;67(6):1218-1228.

18. Winberry WT, Murphy NT, Riggin RM. Methods for determination of indoor air pollutants: EPA methods. Park Ridge, NJ: Noyes Data Corp.; 1993, p. 543-632.

19. Zou C, Shen Z. An optimized in vitro assay for screening compounds that stimulate liver cell glucose utilization with low cytotoxicity. J Pharmacol Toxicol Methods 2007;56(1):58-62. 
20. Schnelle-Kreis J, Gebefugi I, Welzl G, Jaensch T, Kettrup A. Occurrence of particle-associated polycyclic aromatic compounds in ambient air of the city of Munich. Atmos Environ 2001;35(1):71-81.

21. Kawanaka Y, Matsumoto E, Sakamoto K, Wang N, Yun SJ. Size distributions of mutagenic compounds and mutagenicity in atmospheric particulate matter collected with a low-pressure cascade impactor. Atmos Environ 2004;38(14):2125-2132.

22. Fang GC, Wu YS, Wen CC, Lin CK, Huang SH, Rau JY, et al. Concentrations of nano and related ambient air pollutants at a traffic sampling site. Toxicol Ind Health 2005;21(10):259-271.

23. Lough GC, Schauer JJ, Park JS, Shafer MM, Deminter JT, Weinstein JP. Emissions of metals associated with motor vehicle roadways. Environ Sci Technol 2005;39(3):826-836.

24. Sørensen M, Schins RP, Hertel O, Loft S. Transition metals in personal samples of PM2.5 and oxidative stress in human volunteers. Cancer Epidemiol Biomarkers Prev 2005;14(5):1340-1343.

25. Chen LC, Lippmann M. Effects of metals within ambient air particulate matter (PM) on human health. Inhal Toxicol 2009;21(1): $1-31$

26. Rogge WF, Hildemann LM, Mazurek MA, Cass GR, Simonet BR. Sources of fine organic aerosol. 3. Road dust, tire debris, and organometallic brake lining dust: roads as sources and sinks. Environ Sci Technol 1993;27(9):1892-1904.

27. Yang HH, Chiang CF, Lee WJ, Hwang KP, Wu EM. Size distribution and dry deposition of road dust PAHs. Environ Int 1999; 25(5):585-597.

28. Goldberg MS, Burnett RT, Valois MF, Flegel K, Bailar JC 3rd, BrookJ, et al. Associations between ambient air pollution and daily mortality among persons with congestive heart failure. Environ Res 2003;91(1):8-20.
29. Moolgavkar SH. Air pollution and daily mortality in two U.S. counties: season-specific analyses and exposure-response relationships. Inhal Toxicol 2003;15(9):877-907.

30. Becker S, Dailey LA, Soukup JM, Grambow SC, Devlin RB, Huang YC. Seasonal variations in air pollution particle-induced inflammatory mediator release and oxidative stress. Environ Health Perspect 2005;113(8):1032-1038.

31. Keatings VM, Collins PD, Scott DM, Barnes PJ. Differences in interleukin-8 and tumor necrosis factor-alpha in induced sputum from patients with chronic obstructive pulmonary disease or asthma. Am J Respir Crit Care Med 1996;153(2):530-534.

32. Erger RA, Casale TB. Interleukin- 8 is a potent mediator of eosinophil chemotaxis through endothelium and epithelium. Am J Physiol 1995;268(1 Pt 1):L117-L122.

33. Fujii T, Hayashi S, Hogg JC, Vincent R, Van Eeden SF. Particulate matter induces cytokine expression in human bronchial epithelial cells. Am J Respir Cell Mol Biol 2001;25(3):265-271.

34. Li XY, Gilmour PS, Donaldson K, MacNee W. Free radical activity and pro-inflammatory effects of particulate air pollution (PM10) in vivo and in vitro. Thorax 1996;51(12):1216-1222.

35. Hoidal JR. Reactive oxygen species and cell signaling. Am J Respir Cell Mol Biol 2001;25(6):661-663.

36. Hetland RB, Cassee FR, Refsnes M, Schwarze PE, Låg M, Boere AJ, et al. Release of inflammatory cytokines, cell toxicity and apoptosis in epithelial lung cells after exposure to ambient air particles of different size fractions. Toxicol In Vitro 2004;18(2):203-212.

37. Seagrave J, Knall C, McDonald JD, Mauderly JL. Diesel particulate material binds and concentrates a proinflammatory cytokine that causes neutrophil migration. Inhal Toxicol 2004;16 Suppl 1:93-98. 